Portland State University

PDXScholar

7-21-1975

\title{
Chronological Age, Mental Age and Socioeconomic Status Variance in Expressive Preposition Acquisition of Young Children
}

Arthur J. Heckel

Portland State University

Follow this and additional works at: https://pdxscholar.library.pdx.edu/open_access_etds

Part of the Speech Pathology and Audiology Commons Let us know how access to this document benefits you.

Recommended Citation

Heckel, Arthur J., "Chronological Age, Mental Age and Socioeconomic Status Variance in Expressive Preposition Acquisition of Young Children" (1975). Dissertations and Theses. Paper 1943.

https://doi.org/10.15760/etd.1942

This Thesis is brought to you for free and open access. It has been accepted for inclusion in Dissertations and Theses by an authorized administrator of PDXScholar. Please contact us if we can make this document more accessible: pdxscholar@pdx.edu. 
AN ABSTRACT OF THE THESIS OF Arthur J. Heckel for the Master of Science in Speech Pathology and Audiology presented July 21, 1975.

Title: Chronological Age, Mental Age and Socioeconomic Status Variance in Expressive Preposition Acquisition of Young Children.

APPROVED BY MEMBERS OF THE THESIS COMMITTEE:
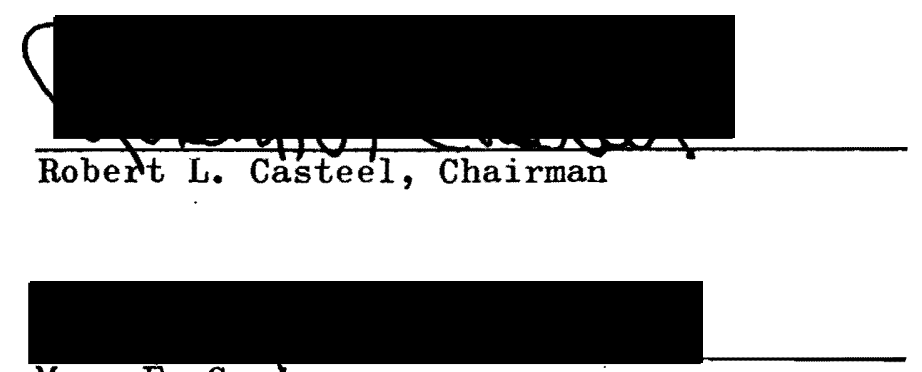
Mary E. Gergon
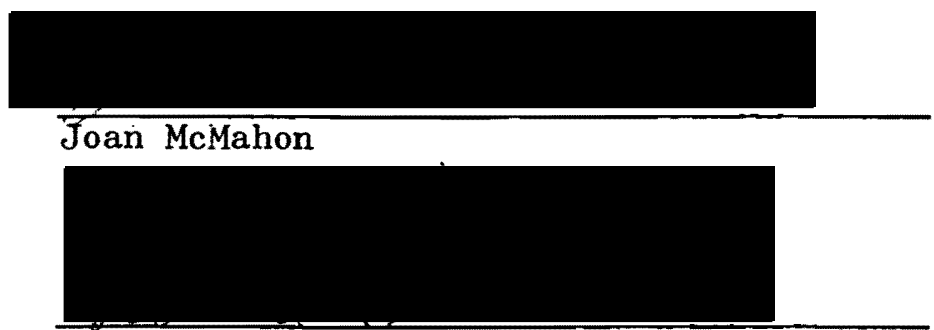

Ronald Smith

The present study was designed to determine the ages at which a sample of children between eighteen and forty-two months verbally and correctly express the fourteen prepositions known to be acquired by age four, using the Revised Expressive Preposition Test (REPT). The REPT was administered to sixty children chosen from day care centers and private homes within the metropolitan area of Portland, 0regon. There was no preference as to the sex, intelligence of the child or socio- 
economic status of the child's family. A statistical analysis was performed to determine the correlation between REPT scores and the child's chronological age, mental age and the socioeconomic status of the child's family.

Results show that expressive prepositions tend to be acquired at different age levels. Each age group tended to use a progressively greater number of the prepositions. None of the eighteen month olds used any of the prepositions. Only one-fourth of the twenty-four month olds used any of the prepositions. Half or more of the thirty month olds expressed the prepositions "under," "on," "in" and "up." Half or more of the thirty-six month olds expressed the prepositions "out of," "at," "in" and "up," but not "under" and "on." Half or more of the forty-two month olds expressed the prepositions "to," "out of," "under," "around," "at," "of," "with" and "up." One hundred per cent of the forty-two month olds also used the prepositions "in" and "on." The prepositions which were never expressed by 50 per cent of any of the children were "behind," "across," "off" and "by."

A statistical analysis of the data revealed a moderate correlation between the children's REPT scores and their chronological ages (.68). Correlation coefficients indicated a high correlation between the children's REPT scores and their combined chronological and mental ages (.82). The children's SES scores did not correlate with REPT scores (1 per cent) when considered together with chronological and mental ages. 
CHRONOLOGICAL AGE, MENTAL AGE AND SOCIOECONOMIC STATUS VARIANCE IN EXPRESSIVE PREPOSITION ACQUISITION OF YOUNG CHILDREN

by

ARTHUR J. HECKEL

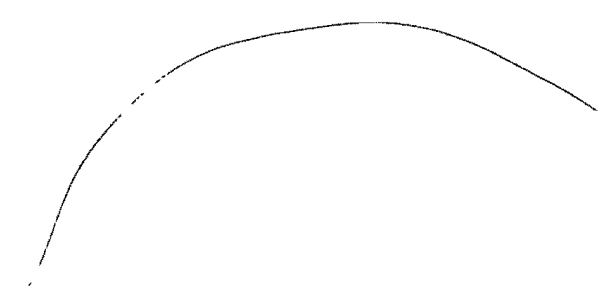

A thesis submitted in partial fulfillment of the requirements for the degree of

MASTER OF SCIENCE IN SPEECH COMMUNICATION: EXPPHASIS SPEECH PATHOLOGY AND AUDIOLOGY 
TO THE OFFICE OF GRADUATE STUDIES AND RESEARCH:

The members of the Committee approve the thesis of Arthur $\mathrm{J}$. Heckel presented July 21, 1975.

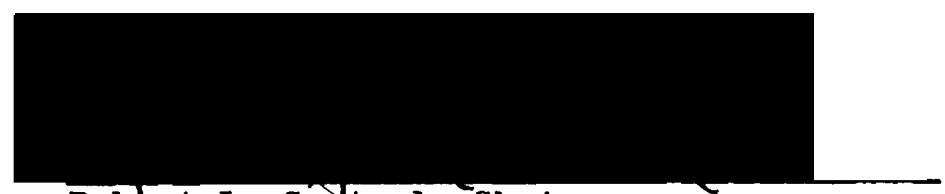

Robert L. Casteel, Chairman

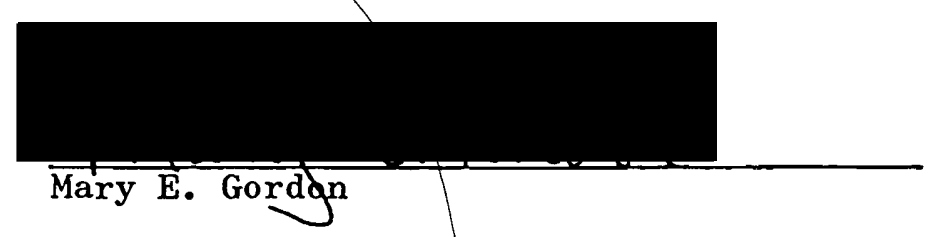

APPROVED :
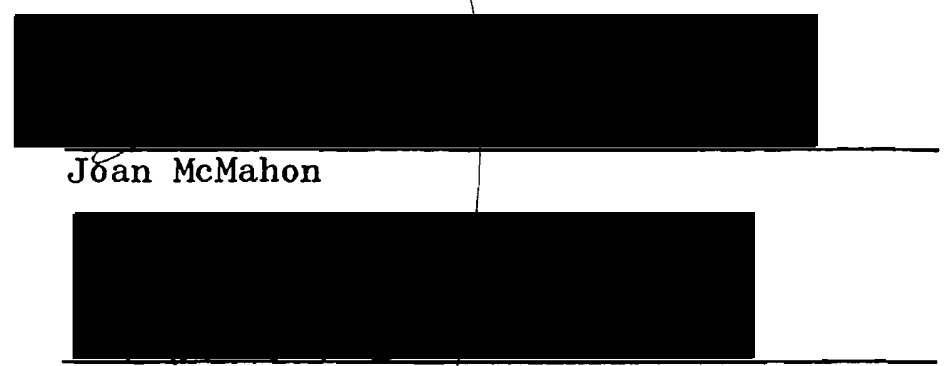

Ronald Smith
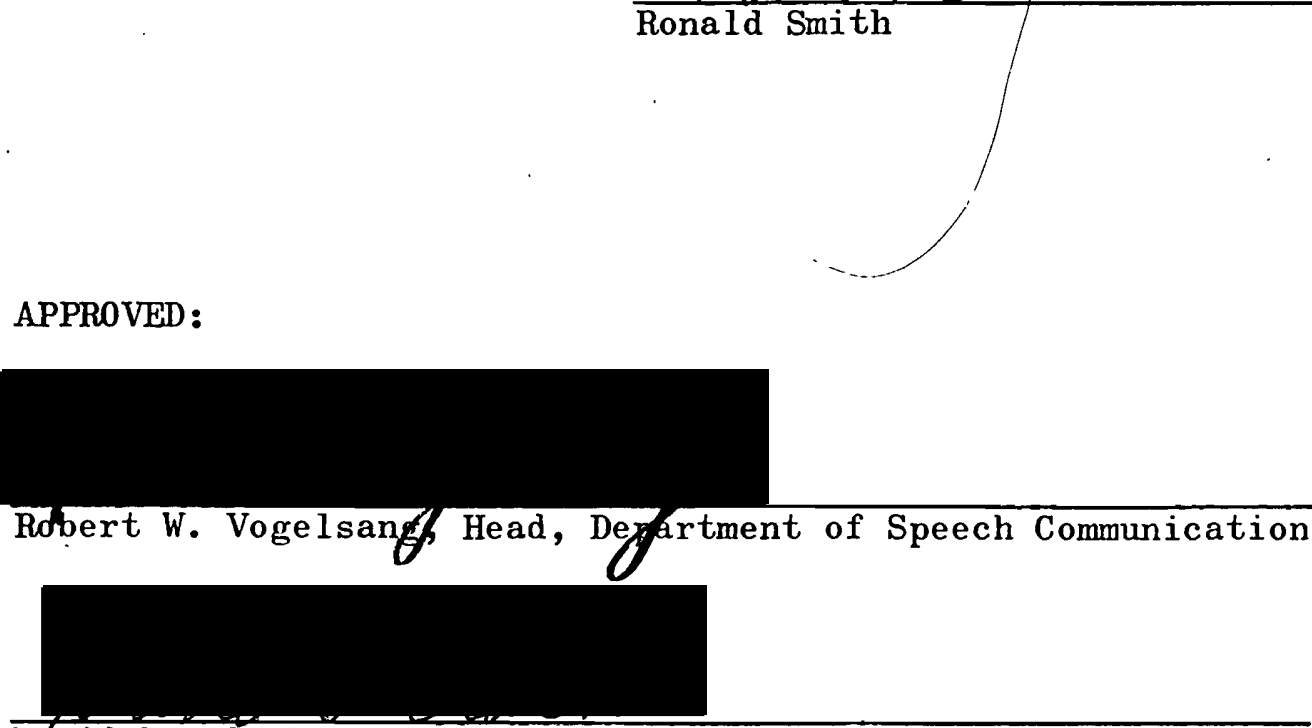

Dávid T. Clark, Dean of Graduate Studies and Research

July 21, 1975 


\section{ACKNOWLEDGMENTS}

I am grateful to Dr. Robert L. Casteel, Chairman, for his direction, guidance and time which he unselfishly provided throughout the production of the entire thesis. Acknowledgment is extended to Mary Gordon and Joan McMahon who also gave their time and efforts. It is a great fortune to have been influenced professionally and academically by my committee.

Special appreciation is extended to Arlene, my dear wife, who offered unhesitatingly her time and energy to assist in locating subjects for the study. Her patience shown during many hours of our absence from each other while I was working on the thesis was outstanding and valued highly. 
TABLE OF CONTENTS

PAGE

ACKNOWLEDGMENTS . . . . . . . . . . . . . . . .

LIST OF TABLES. . . . . . . . . . . . . . . . .

CHAPTER

I INTRODUCTION AND STATEMENT OF THE PROBLEM . . . . •

I. INTRODUCTION: . . . . . . . . . .

II. STATEMENT OF THE PROBLEM . . . . . . . ‘

II REVIEW OF THE LITERATURE. . . . . . . . . . . . .

III METHODS AND PROCEDURES. . . . . . . . . . . .

I. METHODS . . . . . . . . . . 22

Subjects.............. . . 22

Screening . . . . . . . . . . 23

Instrumentation ........... 24

II. PROCEDURES . . . . . . . . . . . 25

Administration of the REPT. . . . . . 25

Scoring . . . . . . . . . . 26

Data Analysis . . . . . . . . . 26

IV RESULTS AND DISCUSSION. . . . . . . . . . 27

I. RESULTS . . . . . . . . . . . 27

II. DISCUSSION . . . . . . . . . . 34 
V SUMMARY AND IMPLICATIONS. • • • • • • • • • • • • • • 45

I. SUMMARY • • • • . . • • • • • . . 45

II. IMPLICATIONS FOR CLINIC AND FUTURE RESEARCH. 47 Clinic. . . . . . . . . . . . . 47

Research. . . . . . . . . . . 47

REFERENCES. . . . . . . . . . . . . . . . 50

APPENDICES. . . . . . . . . . . . . . . . . 55

A COMPREHENSION OF FOUR PREPOSITIONS BY

CHRONOLOGICAL AGE • • • • • • • • • • • 55

B COMPREHENSION OF VARIOUS PREPOSITIONS BY

CHRONOLOGICAL AGE • • • • • • • • • • • • 56

C PERCENTAGE OF PREPOSITIONS COMPREHENDED WHEN

VARIABLES OF AGE AND SOCIOECONOMIC STATUS

ARE CONSIDERED. • • • • • • • • • • • • • . 57

D CCD-CDRC HEARING SCREFNING SCHEDULE • • • • • • • • • 58

E SENTENCES USED TO ELICIT THE FOURTEEN PREPOSITIONS. • 59 


\section{LIST OF TABLES}

TABLE

PAGE

I Number of Prepositions Correctly Expressed at

Each Age Level. . . . . . . . . . . 28

II Analysis of Variance Table for the Revised.

Expressive Preposition Test . . . . . . . .

III Frequency of 0ccurrence of Prepositions Used by 


\section{LIST OF FIGURES}

FIGURE

PAGE

1 A psycholinguistic model of the production and comprehension of utterances. . . . . . . .

2 Comprehension and expression of prepositions by chronological age. . . . . . . . . . . .

3 Comprehension and expression of prepositions by chronological age. . . . . . . . . . . .

4 Frequency of occurrence of prepositions used at various age levels . . . . . . . . . . .

5 Ranges and means of REPT scores of the sixty children ranging in age from eighteen to forty-two months. 


\section{CHAPTER I}

\section{INTRODUCTION AND STATEMENT OF THE PROBLEM}

\section{INTRODUCTION}

A clinician who is working with a speech and/or language disordered child must be concerned with the child's phonemic, morphologic, semantic and syntactic abilities. For this reason many investigations have been conducted in all four areas of children's language development. Most research has been in the area of the development of syntactic structures (Braine, 1963; Brown and Bellugi, 1964; Brown and Fraser, 1964; Fries, 1952; Lee, 1966; Menyuk, 1964; Miller and Ervin, 1964; Weir, 1962); however, very little research has been done in the area of semantics in children's language development. Little, if any, normative data has been collected on the acquisition of expressive prepositions by very young children. This data would be useful for the diagnosis of the young language delayed child and implementation of a program on expressive prepositions for that child.

Linguistic analyses of the English language indicate the importance of prepositions. Pierce (1963) has reported that prepositions, which are pivot class words, are used five times as frequently as open class words, which linguistically categorize the culture. If the pivot class words and open class words in a book were counted, approximately the same number of each class would be found. Pierce (1969) addition- 
ally has pointed out that although speakers use about the same number of pivot class and open class words, Webster's Seventh New Collegiate Dictionary (1969) lists several thousand open class words but only approximately 250 pivot class words. Dewey (1923) analyzed 100,000 words of connected written materials to illustrate the relative frequency of every word. Of the first 100 words which occurred over 100 times in the written material, ten were prepositions.

French et al. (1930) monitored telephone conversations and analyzed the relative frequency of 79,390 words. The researchers discovered that five minor parts of speech (auxillary verbs, pronouns, prepositions, conjunctions and articles) comprise only 5 per cent of the different words but 57 per cent of all the spoken words. Of the total words analyzed, 12,400 were prepositions and conjunctions. These data indicate our language is constructed of relatively few pivot class words which can be set in differing patterns supporting contentive (or open class) words which carry most of the meaning.

Templin (1957) analyzed approximately 24,000 utterances of children from three to eight years of age and reported the mean percentage of prepositions used by the three year olds in relation to other parts of speech was 6.5 per cent. Templin (1957) suggested that by the time the child begins to use phrases and sentences the formal structure of the sentence superimposes limitations and restrictions which, in part, determine the various proportions of usage of prepositions and other parts of speech. She concluded:

After the age of three the parts of speech used in both the total number of words and the different words 
uttered show little change. This is in agreement with other studies and is an indication that the language of children is functioning similarly to the language of adults. At this age the structure of adult grammar has already imposed the pattern of word selection upon the children.

During a six month period, Weir (1962) recorded the utterances of a two year old just before the child was falling asleep in his bedroom. Weir reported the child spoke at least twelve prepositions, including: "to," "up," "by," "in," "on," "under," "around," "behind," "at," "over," "with" and "off." Fries (1940) stated the following nine prepositions, listed according to their frequency of usage, account for over 90 per cent of the prepositions used in a large body of written matter: "of," "in," "to," "for," "at," "on," "from," "with" and "by." Fries stated there may be many widely differing meanings for these nine prepositions, which, in part, may be accounted for by the possibility that nouns carry the feature of the preposition in the deep structure of the language.

Hustead (1974) analyzed the utterances of children between the ages of four and nine years. She manipulated objects and pictures and used carrier phrases and questions to elicit expressive prepositions from the children. She tested six children at each age level. Relative to her data, the present researcher considered a preposition was acquired by age four if the following three conditions were met: 1) at least three of the four year olds used the preposition, 2) at least four of the five year olds used the preposition, and 3) at least five of the six year olds used the preposition. Applying this criteria to her data, this researcher concluded that the following prepositions are acquired expressively by age four: "across," "around," "at," "behind," 
"by," "in," "of," "off," "out of," "to," "up," "under" and "with."

Hustead's data do not show at what age levels these fourteen prepositions begin to appear in the language of children younger than four years of age.

Since these fourteen expressive prepositions may occur in the language of young children, it would be valuable for the parent of very young children, as well as the language clinician, to know at what age levels young children below four years of age express each of the fourteen prepositions. Should a young child be delayed in expressing prepositions, the language clinician and parent could consider the initiation of a prepositional language program based upon their knowledge of general acquisition.

\section{STATEMENT OF THE PROBLEM}

The present study was designed to determine the ages at which a sample of children between eighteen and forty-two months verbally and correctly express various prepositions known to be acquired by age four.

This researcher sought to answer the following questions:

1. Which of the various fourteen prepositions appear at eighteen months, at twenty-four months, at thirty months, at thirty-six months, and at forty-two months?

2. How many of the various prepositions appear at each of the above age levels?

3. In what order do the various prepositions appear in the expressive language of the children?

4. To what extent will chronological age, mental age and socioeconomic status account for the variability of responses given by the children? 
5. Was the Revised Expressive Preposition Test an appropriate tool to evaluate expressive prepositions in very young children? 


\section{CHAPTER II}

\section{REVIEW OF THE LITERATURE}

Before one can understand how a child learns prepositions, one must understand generally how language is learned. The psycholinguistic approach to language acquisition views language as consisting of three large units: phonological information, syntactic information and semantic information. Phonological information refers to the set of matrices of distinctive features of the phonemes used in a particular language, as well as the set of rules used in combining the set of matrices. Syntactic information consists of base structure rules, transformational rules and morphological rules and describes the functional relationships in sentences. Semantic information includes the lexicon or dictionary in which each morpheme is enumerated by the properties describing it (Menyuk, 1971).

Psycholinguists (Bloom, 1971; Chomsky, 1957; Hopper and Naremore, 1973; McNeil1, 1970; Menyuk, 1969; Menyuk, 1971; Streng, 1972; Wales and Marshall, 1968) purport that the child learning his language has the capacity to search out and store abstract aspects of his language. Figure 1 illustrates how the child comprehends language and produces utterances (Menyuk, 1971). The arrows flowing from top to bottom indicate a process of production of an utterance, whereas the arrows flowing from bottom to top indicate the process of comprehension. Menyuk (1971) stated: 
It should be noted that there are also arrows indicating cross references between semantic rules and syntactic rules, between semantic rules and phonological rules, and between syntactic rules and phonological rules, indicating that perhaps tentative hypotheses are reached which are then checked by reference to parts of the system before the final stage of comprehension or production is reached.

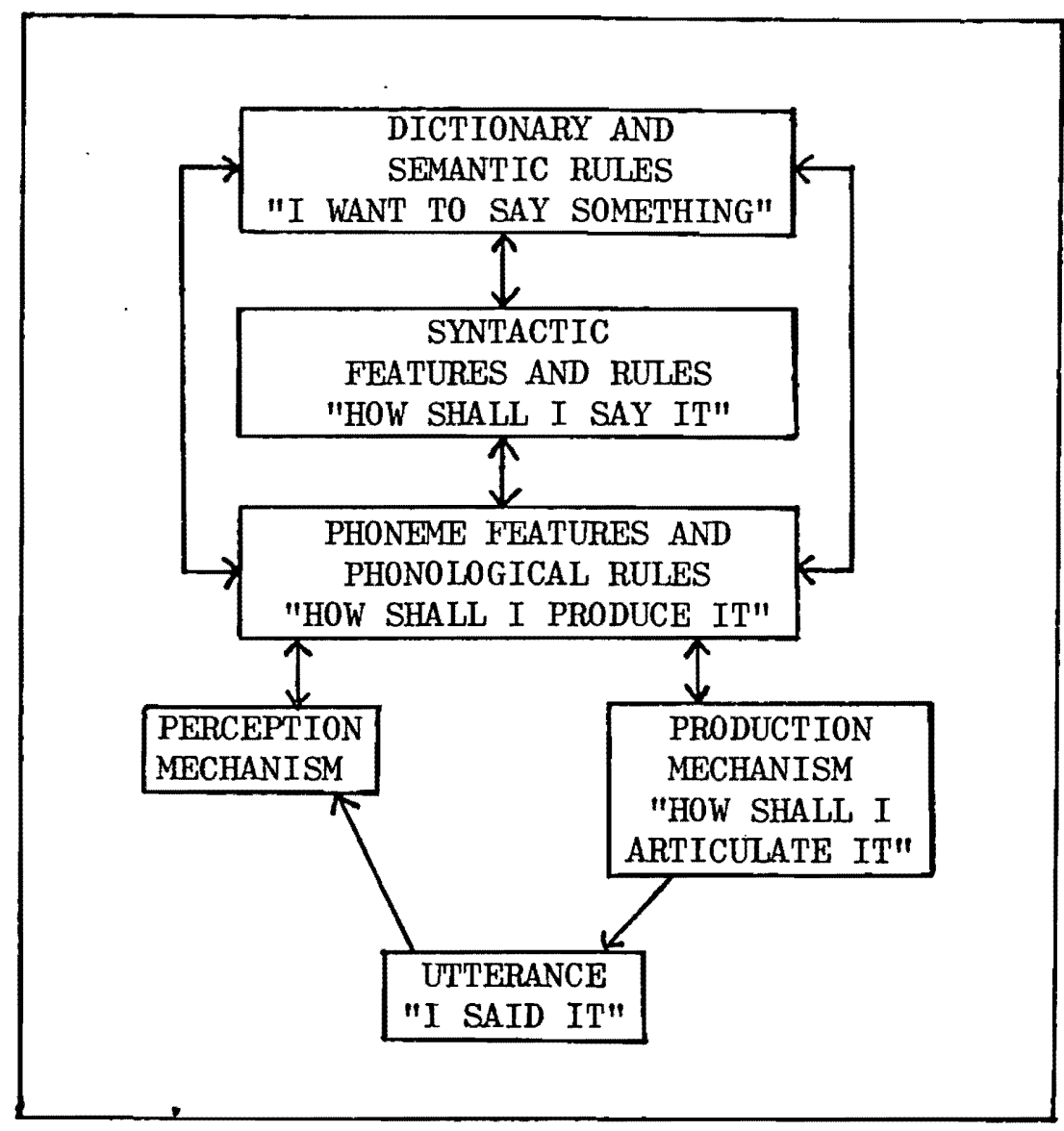

Figure 1. A psycholinguistic model of the production and comprehension of utterances (from Menyuk, 1971).

Prepositions, as well as other lexical items in the language, are acquired through the processes of perception and comprehension. Korzybski's work (1958) concerning abstraction furnishes a framework 
from which to look at language perception and expression. His Structural Differential is summarized by Lee (1959) as a way of presenting each level of abstraction through which the child moves.

The first level represents the silent world of stimuli outside the organism of which only a very small amount reaches the child's sense organs. It operates completely separately from his nervous system.

The second level is the area where images in the world are implanted in the nervous system of the organism. The normal child is able to abstract comonalities of stimuli and to perceive his world in definite groups for which he may use utterances to symbolize the groups.

Korzybski then described the third or verbal level which is composed of four sub-levels. Lee (1959) stated, "The first is the level of individual names, proper nouns, words which stand for single objects or particular people." An example would be one of the child's first words, "mommy." The next verbal sub-level is the use of a word to describe a certain abstraction based on commonly perceived similarities. The child used the word "mommy" to label his own mother and did not label all other adult-females. Now he continues to correctly use "mommy" to denote his own mother and labels all other adult-females "ladies." Probably all verbs fall into this second-verbal level. Lee (1959) stated that nouns usually appear in a child's vocabulary before verbs. The third sub-level is a higher verbal level of abstraction in which the child categorizes several types of things, and groups them by one word. This level is illustrated by grouping "carrots," "peas," "potatoes," "corn," etc., into "vegetables." The next sub-level is called the inferential level and refers to the ability to anticipate in 
a particular point in time and space what has happened or will happen. The child who abstracts at this level is able to look at a photograph and describe what may have occurred before the moment and what likely will occur after the moment.

It is at these higher levels of abstraction that prepositions become meaningful to the child. Each preposition has a territory of meaning. For example, "on," according to Webster (1969), means "over and in contact with." "The car is on the box" means that the car must be both over or above and in contact with the box. This semantic field for "on" is rather definitive. Lee (1959) has stated that prepositions and other

\begin{abstract}
"little words are maps for a host of subtle relationships and high-order abstractions. They are the means by which perceptual experiences are structured and ordered into our own particular linguistic patterns. When we learn language, we learn to perceive and abstract what our language has words for."
\end{abstract}

It seems obvious that children have some kind of semantic system early in their linguistic development. McNeill (1970), as well as Hopper and Naremore (1973), suggested a child's first words stand for whole sentences. This idea is referred to as the holophrastic theory, for "mama" may mean "Here is mama," "Come here, mama," etc. The child's words often represent more than the adult definition of the same words. McNeill (1970) stated, "Each meaning embodies a particular grammatical relation and each word is paired with several such meanings." This theory may be satisfactory for the child with a limited vocabulary, but as he wishes to express greater and fuller meaning, the problems of limited memory and ambiguity become apparent. The creation of new words 
into the dictionary would satisfy the ambiguity but would place an increased burden on memory. As the child would express more complex semantic and syntactic relationships, the holophrastic theory would need to be altered.

Consequently, McNeill (1970) and Hopper and Naremore (1973) have suggested a word dictionary approach. McNeill stated:

In moving from a holophrastic to a sentence dictionary, a child continues to record undifferentiated semantic information: The definition of one sentence is not related to the definition of any other. In moving from a sentence to a word dictionary a fundamental change is made in the format of the dictionary entries themselves. A child begins to elaborate a system of semantic features and sentences come to be interrelated by rules for using dictionary entries.

As the child becomes older and learns to combine words to make sentences, his dictionary definitions become more like the adult's as he adjusts his meanings of words and their combinations to be more like the adult's. "We had a ball" might be understood by the child as "We had a spherical object which one throws" since the young child's store of semantic information is incomplete and he misuses words (Hopper and Naremore, 1973). Vygotsky (1962) has explained how in any one given language lexical items change in their meaning over a period of time. The process usually begins by a word having a meaning defined by several attributes. Over time one or two of these attributes are abstracted and applied to another item, situation, etc., and used to describe a different aspect of the language. As an example Vygotsky cited a child's use of the word "bow-wow." At first the child used it to refer to a china figurine of a girl, then to a dog barking in the yard, then to a furry piece of an animal's head with glass eyes, then to a rubber 
doll, and then to his father's cuff links. Vygotsky concluded that the child categorized things, using "bow-wow" by first grouping dogs and small oblong objects and secondly, shiny round objects and the cuff links. The "criterial attribute" was oblong shape or shiny surfaces. Lewis (1963) observed a child who initially used one word "tee" for several animals but used "goggie" for his toy dog. Eventually each animal began to receive its own name, "tee" was no longer used, and "goggie" remained. Lewis termed this "contraction" because the child used more lexical labels and eliminated his use of "tee." Additionally, "hosh" referred to a large dog as well as to a horse. However, when the child consistently referred to his small dog and his toy dog as "goggie," "hosh" (large dog) became "biggie goggie." Lewis called this "expansion" because the child was accurately combining the concepts "biggie" and "goggie" to label the concept "large dog." Perhaps the child categorized all animals under one word because of their manipulative or functional similarity (Lewis, 1963).

Menyuk (1971), on the other hand, suggested the child is making a conceptual differentiation rather than merely grouping objects according to their manipulative or functional similarity. Things in the environment may be categorized according to their manipulative similarity based exclusively on a visible attribute level, but this seems to be oversimplifying the process. Rather, Menyuk (1971) suggested a child categorizes things according to whether or not the object possesses a particular characteristic or not, i.e., 士attribute. Therefore, the child may be able to differentiate objects, relationships, experiences into \pm human, \pm large, \pm animate, etc. In the end, a child may refer to 
-human, +large, tanimate as "biggie goggie."

It seems that these generalizations and differentiations which children make with a set of objects (animals) may occur within other semantic fields as well. Menyuk (1971) has noted that a child may refer to all males including his own father as "daddy," but may not refer to all females as "mommy." She concluded, "It should be stressed, therefore, that the property understood does not seem to be based on the conceptual generalization (for example, +male) but probably on a set of specific and perhaps idiosyncratic observations."

Hopper and Naremore (1973) stated that the child learns the meanings of words by attaching "semantic markers" to each individual word. The semantic markers correspond to the dictionary entries. For example, "dog" has the following semantic markers: "furry," "four legs," "barks," etc. The acquisition of a set of semantic markers is called "concept development." McNeill (1970) has suggested that the child begins his word dictionary around eighteen months. The concept of word dictionary is strikingly similar to Menyuk's (1971) conceptual differentiation and harmonizes with the concepts of sentence and phrase transformations. Hypothetically, the child enlarges his word dictionary in two directions. First, the child may have an incomplete list of semantic features for each word entry, and he may add horizontally to complete the dictionary entries of the words already acquired. Secondly, many semantic markers are entered into the dictionary when the word is entered, but the entries are separated from each other so that the semantic markers appear unrelated. These words would have some of the same semantic properties, and development would occur vertically uniting 
common semantic occurrences.

Hopper and Naremore (1973) and others (Menyuk, 1971; McNeill, 1970) have suggested children also learn the meaning of words based on the word's usage in only certain syntactical contexts, i.e., "selection restrictions." Hopper and Naremore (1973) explained:

It is the necessity for matching semantic features with selection restrictions that can cause problems for a child when he begins to use words in combinations. If the concept that corresponds with a given word for the child does not contain all the necessary semantic features, then errors will occur when the child begins to use that word in combination with other words.

The child learns that "bark on the tree" is meaningful and "bark on the dog" is not meaningful, that "the dog barks loudly" is meaningful and "the tree barks loudly" is not meaningful. Werner and Kaplan (1964) have cited an example of a child's construction of two words which are meaningful to him only in specific sentence contexts. "Brush mama" is understood but "brush hat" is not understood. This ability/inability may be the result of a limited set of individual, lexical properties of words which exist from individual sentence contexts. Each set of properties is correctly modified as new contexts are recorded and analyzed by the child. McNeill (1970) has added, "Every dictionary entry contains selection restrictions setting forth the word's allowable semantic contexts."

Menyuk (1971) stated there is a strong indication that words are not used separately and meaningfully from their sentence contexts until somewhat after age ten. She contended:

Since lexical items may have different properties depending on the context in which they are used, it is possible that children acquire only a limited or restricted set of 
properties for particular lexical items, which is derived from the syntactic context in which the child frequently finds or uses them.

For example, based on a particular sentence context a six year old child may think of "bottle" exclusively as a thing out of which you pour something. A twelve or thirteen year old child will use many varied lexical items to define bottle which a six year old has not yet acquired (Werner and Kaplan, 1964). Therefore, for the older child, "bottle" and many other related concepts have some identical semantic properties, although the younger child may not realize it and classify the concepts in his vocabulary under mutually exclusive syntactic headings with a separate set(s) of properties (Menyuk, 1971).

Studies conducted with children on word associations have helped in the understanding of the semantic functioning of children. Hopper and Naremore (1973) have stated word associations are more predictable for older children than for younger. The association for older children will be the same as, or opposite of, the stimulus. For very young children associations are less predictable to the point of randomness, probably because their dictionary entries are less complete than adults'. Palermo and Jenkins (1965) have reported a study done with school age children concerning the types of word association responses. Second-graders not only produced more paradigmatic responses (for example, "cat" in response to "dog") quicker than first-graders but also gave more contrast (for example, "black" in response to "white". or "night" in response to "day") and superordinate responses (for example, "color" in response to "red" or "number" in response to "five"). If we understand that these responses demand identity of the syntactic class 
and of a general semantic property, then the increase in paradigmatic responses is in part explained by maturation. A small number of properties listed for any lexical item might not include those properties which associate members of the identical syntactic class. Menyuk (1971) stated the word "square" may elicit "box" most frequently for first-graders and "round" for fourth-graders. It is unlikely that "square-box" stands as one word by itself for first-graders. Rather, it seems that "square" in their dictionary does not have the property "shape," and cannot be contrasted with "round" as fourth-graders do. Apparently, "square" and "box" have at least one identical semantic property for first-graders.

Menyuk (1971) has stated that other studies have indicated 1) children have a somewhat limited set of lexical properties for understanding lexical items until they achieve a certain level of maturation, and 2) children will use the same verbal response for several lexical items until they reach that level of maturation. For example, Lumsden and Poteat (1968) reported preschool children almost always describe an object as being "bigger" than its comparator, although the stimulus material used was four times "taller" than the "shorter" stimulus material. When compared to the younger ones, older children performed quite differently in this task. Menyuk (1971) commented:

Indeed, the behavior of the younger children in this study . . indicates that they may assign different lexical items to the same or overlapping sets of properties in a manner similar to that of very young children, who are acquiring the meaning of lexical items in a semantic field. It is interesting to note that lexical items which have properties which are presumably easily visible (size, weight, height, etc.) are still non- 
differentiated by sixth-grade children. Again, we wonder about developmental stages in the differentiation of properties of lexical items in various semantic fields.

Asch and Nerlove (1960) explored children's understanding of double-function words ("sweet," "hard," etc.), which could be applied to both humans and inanimate objects. As would be expected, children from three to six years of age used the physical properties to describe objects. 0lder children demonstrated an increased ability to state the dual meaning of the lexical items. The researchers concluded that double-function terms, at first, have one set of properties largely consisting of perceivable objects and actions and one verbal response. Later appears another set of properties and verbal responses distinguishable from the earlier set.

Quine (1964) has pointed out that in order to develop other concepts a child first must develop the concept of the permanency of recurring objects. For example, the moon tonight is the same moon yesterday and tomorrow; they are not three different moons. The child needs to learn that the apple he ate for yesterday's lunch is not the same apple in the store, nor is it "that apple" or "this apple" or "not an apple." "Apple" is not truly understood as a term unless the child can differentiate between the concept "apple," its abstract label and the concrete examples of that concept "apple." Hopper and Naremore (1973) maintained, "To say that the child understands these various uses of a word implies that the child has developed a concept to go with a certain label." There is a difference between a child knowing the correct label for a concept versus being able to assign just any label to a concept. 
McNeill (1970) has pointed out that semantic development in a child is consistently slower than phonological or syntactic development and has suggested that the complexity of information in a dictionary may account, in part, for this slow development. The development of semantics seems to depend more upon intellectual maturity than development of grammar. Additionally, the abstractness of dictionary entries may account for slow lexical development. The outward forms of words do not suggest underlying semantic regularities. McNeill explained, "Unlike syntactic abstractions, which are systematically related to surface structure by transformations, the semantic relations between words and deep structures are unsystematic."

McNeill's (1970) explanation of slow lexical development may help explain Menyuk's question (1969) as to why children do not always use prepositions correctly. Menyuk suggested that perhaps children have problems using the correct preposition because they have difficulty selecting the correct preposition to denote place, manner and time in specific contexts. Perhaps, Menyuk suggested, the child lacks clear definitions for these concepts; and, therefore, he may elaborate by giving a definition to the preposition he wants to use ("he gets all the way close" for "almost near") or he may elaborate because he does not clearly understand the preposition he uses ("he went beside from the house" for simply "beside"). Younger children tend to substitute prepositions ("she wants to stay at the puppy" rather than "she wants to stay with the puppy"). Menyuk (1969) maintained, "After certain members of this class are a part of the child's dictionary he may use them conjointly to attempt to express meanings for which he has not yet ac- 
quired the appropriate lexical items."

Brown and Bellugi (1964) have observed prepositions are often omitted from children's language because the children have never heard the prepositions in other speakers' speech. Heavy stress is placed on contentive words rather than functor words (such as prepositions), and if the child does not hear the weakly stressed prepositions, he usually fails to reproduce them.

Werner and Kaplan (1964) have described studies which show that about age six 82 per cent of lexical items are defined in terms of concrete action (for example, a bottle is "where you pour something out of"). Since prepositions are difficult to define in concrete terms, it is difficult for the child to use them.

Ervin-Tripp (1966) has described that nouns, which appear first, refer to items with peculiar sizes and visual contours and that verbs refer to movement of animals and people. Menyuk (1971) wrote, "In other words, the verb or easily visible properties may be the first properties that are acquired by the child in his use of a lexical item." Menyuk (1969) further intimated that of the three categories of prepositional phrases (place, time and manner), those indicating place appear first in the child's lexicon and the prepositional phrases of manner and time áppear sometime later. Therefore, with each category of preposition the exact prepositional morpheme must be accurately selected to be used with the noun phrase and its context. For example, a child at two years, eight months, will inappropriately use the preposition and article: "Put in head" for "Put (it) on the head" and "He's going up in the ladder" for "He's going up the ladder." - Menyuk sum- 
marized:

The child is in the process of acquiring a class in the language whereas at later stages, he is analyzing how the class is used in specific contexts in his language. The development of this class in the language seems to be first a general observation, perhaps simply phonological (something appears before topics), which is applied generatively and sometimes inappropriately. Then the child expresses a particular instance of a topic that he is dealing with at the moment. This also seems to be the case in the development of prepositional phrases.

In a study of comprehension of prepositions in children, Slobin (1966) found that comprehension was directed to a specific characteristic of the preposition. He cited that when a child was asked to place a block under a table, he was able to do so. But when asked to place the block under a ring which was on the table, he first put the ring under the table and then put the block under the ring. This behavior suggested that not all semantic elements of the lexical items (prepositions) used are fully understood or accurately used by the child..

The studies of several linguists have shown that children tend to acquire and express prepositions a few at a time developmentally, rather than to acquire them as a whole class. According to Lillywhite (1958), prepositions begin to appear in the child's speech between ages three and four. Bereiter and Engelmann (1966) suggested that for a child to succeed academically in a school setting, he must be able to describe arrangements of objects correctly using the following prepositions: "on," "in," "over," "under" and "between."

More specifically, the following tests have suggested the development of preposition comprehension according to chronological ages: Houston Test for Language Development (Crabtree, 1958; Appendix A), 
C.C.D. Language Manual (University of Oregon Medical School, 1957;

Appendix B) and Denver Developmental Screening Test (Frankenburg and Dodds, 1967; Appendix C). The Developmental Age Study (Baker and Dudrey, 1968; Figure 2) and Sequenced Inventory of Language Development (Hendrick and Prather, 1970; Figure 3) deal with both comprehension and expression of prepositions. The Utah Test of Language Development (Mecham et al., 1969) evaluates the understanding of "in" and "by" for two and three year old children. The Boehm Test of Basic Concepts (1969) tests the following concepts for kindergarten, first and second graders: "through," "next to," "inside," "around," "over," "between," "after," "below," and "above." The Daberon (Danzer et al., 1972) evaluates the understanding of "in," "under," "behind," "on," "in front of" and "next to" for three year olds.

\section{Months}

Expresses: Uses "after." Uses space words: "on," "up high," "in," "out," "fall down" and "turn around."

\section{Months}

Expresses: "up," "down," "way up," "in here," "under the table" and "around the table."

36 Months

Understands and uses 31 prepositions.

Expresses: "in the train," "over" and "around."

42 Months

Comprehends: "on," "in front of," "behind" and "under."

Figure 2. Comprehension and expression of prepositions by chronological age (From Baker and Dudrey, 1968). 
Comprehension

21-23 Months: "in."
27-29 Months: "on."
30-32 Months: "beside."
39-41 Months: "under."

Expression

30-32 Months: "in" and "on."

39-41 Months: "under" and "beside."

Figure 3. Comprehension and expression of prepositions by chronological age (From Hendrick and Prather, 1970).

Although the several tests above deal with comprehension of prepositions, a review of the literature reveals little data as to which of various prepositions are used expressively by young children between ages eighteen and forty-two months. Hustead's (1974) study of expressive preposition acquisition in four through nine year olds revealed fourteen prepositions which are acquired by age four. She did not test children below four years to determine at what ages they began using prepositions.

The classroom teacher, language clinician and parent of young children should understand how language is acquired and have available a tool to indicate which prepositions are found in the speech of young children at particular ages. Should the clinician determine that the child is delayed in his expressive use of prepositions, the clinician needs to have an index whereby he can devise a language program to teach the prepositions which the child lacks in his communicative skills. 


\section{CHAPTER III}

\section{METHODS AND PROCEDURES}

\section{METHODS}

\section{Subjects}

Sixty children consisting of five groups of twelve were tested within one month of their designated ages. They comprised each of the following age groups: eighteen months, twenty-four months, thirty months, thirty-six months and forty-two months. The sixty subjects were randomly selected, with no preference as to the sex of the child, from the Sunday School Department of several churches, private homes and several day nurseries and day care centers within the metropolitan area of Portland, Oregon. Each Sunday school pastor, mother or day care center director was contacted by phone, and subsequently in person, to request permission for his/her students'/child's participation as subjects in the study.

After each subject was selected, one of the child's parents filled out a questionnaire on salary, occupation and level of education of both parents. Working Paper Number Fifteen, U.S. Bureau of the Census (1963), was used to acquire data to compute socioeconomic status for each child's family. The Ammons and Ammons Quick Test (QT), Form 1, (1962) was administered to all subjects to obtain mental age scores for correlation analysis with socioeconomic status scores, chronological age and Revised Expressive Preposition Test (REPT) scores. 


\section{Screening}

Children with reported hearing losses, physical handicaps or speech defects which would interfere with the intelligibility or verbal production of the prepositions were excluded from the study. Criteria for normal language and speech were established according to Lillywhite's (1958) guidelines. He stated that eighteen month olds should have 15 to 20 words as reported by the parent, two year olds should have between 100 to 200 words as reported by the parent, thirty month olds should have between 300 to 500 words with some two word responses, thirty-six month olds should have about 600 words with some three word responses, and forty-two month olds should have between 600 to 1000 words with three to four word responses. Evidence of normal language development was determined by requesting the parents to report what the child said and comparing it with Lillywhite's guidelines, or by having the researcher track what the child said during a casual conversation period before the formal evaluation and comparing it with Lillywhite's guidelines. Specifically, normal language for all eighteen month olds was determined by requesting the parent to report or by having the examiner record ten words in the child's expressive language. Normal language for all twenty-four month olds was similarly determined by requesting the parent to report or by having the examiner record three two-word responses in the child's language. The parent of all thirty month olds reported or the researcher recorded six two-word responses in the child's expressive language in order for the child to be included in the study. The parent of all thirty-six month olds reported or the researcher recorded three three-word responses in the child's language 
in order for the child to be included in the study. Normal language for all forty-two month olds was determined by the parent reporting or the examiner recording three four-word responses in the child's expressive language. If the child did not meet criteria for normal language, he was excluded from the study.

Each subject was required to have hearing within normal limits. Audiometric testing for the thirty-six and forty-two month olds had been completed earlier in the year by the Oregon State Board of Health. All other hearing screening was performed at the time of the interview by the examiner using the hearing screening schedule developed at the Crippled Children's Division and Child Development and Rehabilitation Center, University of Oregon Health Sciences Center, Portland, 0regon (See Appendix D). For all hearing testing, each subject met the hearing criteria for his age level in order to be included in the study.

\section{Instrumentation}

The Revised Expressive Preposition Test (REPT) was modified from the Expressive Preposition Test (EPT; Hustead, 1974). Individual stimulus, procedure and response items were shortened and made more concrete primarily because of the young age of the children. Both the EPT and REPT procedures for eliciting responses were patterned after the "Functional Use of Prepositions" subtest of the Daberon (1972). The REPT was administered individually to each of the sixty subjects. 


\section{PROCEDURES}

\section{Administration of the REPT}

Each child met the screening criteria in order to be included in the study. Each child was tested individually in a familiar, quiet room of his home or school. The researcher and child sat opposite each other with a small table between them. One parent was allowed in the room with the examiner and child but was instructed to refrain from providing cues or feedback for the child. The child was allowed to sit on the parent's lap at the recommendation of the parent. All testing supplies were placed on the floor by the researcher and presented. individually on the table to the child. Before testing began the researcher put the child at ease by casual conversation.

The testing materials and the researcher's verbal stimuli for eliciting the child's verbal responses were presented to the child one at a time. The subject's verbal expression of each of the fourteen prepositions was tested by having him explain where an object was located or describe some act of the examiner. For example, when the researcher wanted to elicit the preposition "by," a small toy car was placed by a box on the table. The question, "Where is the car?" was asked to elicit the response "by the box." (See Appendix E for a complete list of the prepositions and the manner in which they were elicited.)

If the child did not respond or if he requested a repetition of the stimulus either verbally or by exhibiting a puzzled look on his face, the examiner repeated the stimulus up to three times. 


\section{Scoring}

This examiner scored each test by giving one point for each correct response and no points for an incorrect response. Total score possible was fourteen points. In order for any given response to be accepted as correct, each child had to verbalize the correct preposition or one of the acceptable alternatives in an intelligible manner (See Appendix E).

Data Analysis

Multiple regression analysis was used for the statistical analysis. 


\section{CHAPTER IV}

\section{RESULTS AND DISCUSSION}

\section{RESULTS}

This study was designed to determine the ages at which a sample of children between eighteen and forty-two months verbally and correctly express various prepositions known to be acquired by age four.

The first question asked in this research project was which of the various prepositions appear at the various age levels tested. Table I shows the number of correct responses given by the children at each age level. Table I reveals none of the eighteen month olds expressively used any of the fourteen prepositions tested. At the twenty-four month level, three children used the preposition "on," two children used the prepositions "up" and "on," and only one child the prepositions "under," "around," "at," "of" and "to." The remaining five prepositions were not expressed by any of the twenty-four month olds. The mean number of correct responses of these children was 1.00 . With a sample number of twelve children, this implies that on the average each twentyfour month old expressed one preposition; however, only five of the twelve children expressed the prepositions for their age group. Seven of the twelve expressed none of the prepositions.

At the thirty month level, none of the children used "behind," two used "by," three used "around," "across," "off" and "to," four used "out of" and "with," five used "at" and "of," six used "under," eight 
used "on," ten used "in" and eleven used "up." The mean number of correct responses given by this age level was 5.50 .

\section{TABLE I}

NUMBER OF PREPOSITIONS CORRECTLY

EXPRESSED AT FACH AGE LEVEL

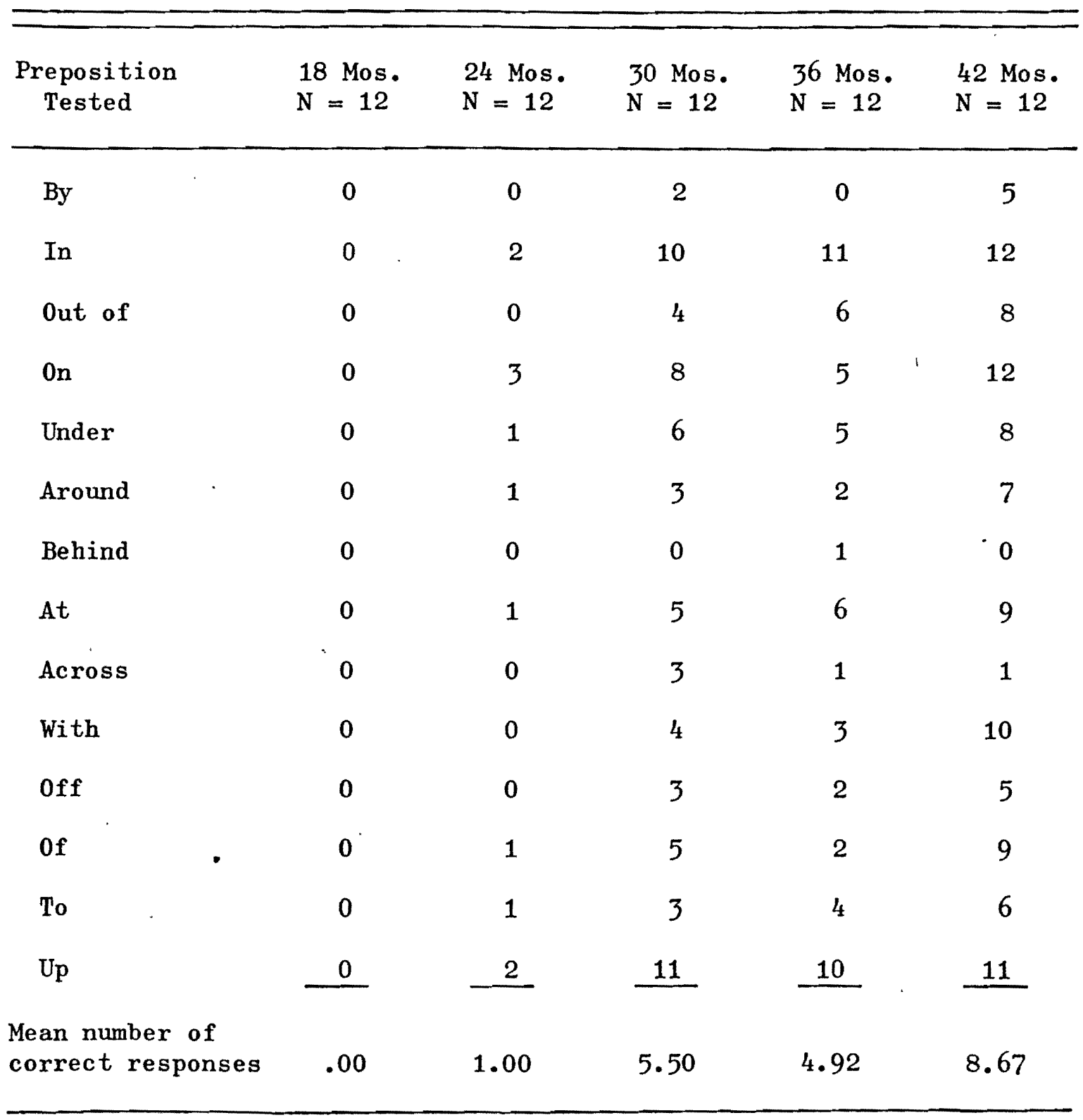


At the thirty-six month level, none of the children used the preposition "by," one used "behind" and "across," two used "around," "off" and "of," three used "with," four used "to," five used "on" and "under," six used "out of" and "at," ten used "up," and eleven used "in." The mean number of correct responses given by this age group was 4.92. On the average they gave .58 fewer correct responses than did the thirty month olds.

At the forty-two month level, none of the children used the word "behind," one used "across," five used "by" and "off," six used "to," seven used "around," eight used "out of" and "under," nine used "at" and "of," ten used "with," eleven used "up" and all twelve used the words "in" and "on." The mean number of correct responses for these children was 8.67 .

Table I additionally shows that the mean number of correct responses for all children ranged from .00 to 8.67 points of a possible fourteen points. Only at the forty-two month level did the children respond with 100 per cent accuracy on the two prepositions "in" and "on." All fourteen prepositions were expressed at least once by at least one of the children, but the preposition "behind" was used by only one of the sixty children and that was by a thirty-six month old.

The second question in this investigation was how many of the various prepositions appear at each of the above age levels. If 50 per cent of the children or more expressed the preposition at any given age level, it was decided that the preposition "appeared" at that level. Figure 4 illustrates that no prepositions appeared at the eighteen month level. At the twenty-four month level, eight of the fourteen 

(o) 18 Months
(x) 24 Months
(v) 30 Months
(+) 36 Months
(=) 42 Months



Figure 4. Frequency of occurrence of prepositions used at various age levels. 
prepositions tested were expressed by at least one but no more than three of the twelve subjects (less than 25 per cent). It is safe to say that twenty-four month olds use very few prepositions. At the thirty month level, four of the fourteen prepositions tested were expressed by at least half of the subjects ("under," "on,". "in," and "up"). Four other prepositions were expressed by 30 to 45 per cent of the subjects and another five prepositions were expressed by 8 to 25 per cent of them. At the thirty-six month level, four of the fourteen prepositions were expressed by at least half of the subjects with two of the prepositions being the same as two of the prepositions used at the thirty month level ("out of," "at," "in" and "up"). Another three prepositions were expressed by 30 to 45 per cent of the subjects and another six prepositions were expressed by 8 to 25 per cent of them. Finally, at forty-two months, ten of the fourteen prepositions were expressed by over half of the subjects ("to," "out of," "under," "around," "at," "of," "with," "up," "in" and "on"). Two more prepositions were expressed by 42 per cent of them and two more prepositions by less than 9 per cent of them. Four prepositions ("behind," "across," "off" and "by") were never expressed by at least half of the children in any of the five age levels.

The third question asked in this research investigation was in what order do the various prepositions appear in the expressive language of children. Figure 4 lists the number and percentage of children at the five age levels who used the various prepositions. If 50 per cent of the children or more is employed to define that a preposition appeared at a given age level, then the words "under" and "on" appeared in 
the expressive language of thirty month olds. "Under" was used by only 42 per cent of the thirty-six month olds but by 58 per cent of the forty-two month olds. "0n" was used by only 42 per cent of the thirtysix month olds but by 100 per cent of the forty-two month olds. Based on these data, there is some uncertainty as to when the concepts "under" and "on" become stabilized in the expressive vocabulary of children. Both prepositions were used by thirty month olds, but their usage decreased somewhat at the thirty-six month level; however, at forty-two months the prepositions became stabilized.

The concepts "in" and "up" were used by over 80 per cent of all the thirty, thirty-six and forty-two month olds, with 100 per cent of the forty-two month olds using "in." Nearly all thirty month olds and older used the prepositions "in" and "up."

In addition to the prepositions already discussed, "out of" and "at" were two prepositions used by half of the thirty-six month olds. With some caution it may be stated that the words "out of" and "at" appeared around thirty-six months. At the forty-two month level, 67 per cent of the children used "out of" and 75 per cent "at."

Finally, "to" was expressed by half of the forty-two month olds; "around" was used by over half ( 58 per cent) of the forty-two month olds as was "of" ( 75 per cent); and "with" was used by a large majority of the forty-two month olds (83 per cent). It was concluded that "to," "around," "of" and "with," as well as "out of" and "at," appeared in the expressive language of the forty-two month olds.

The fourth question in this investigation was to what extent will chronological age, mental age and socioeconomic status account for the 
variability of responses given by the children. The analysis of variance shown in Table II reveals that nearly 47 per cent of the variability can be accounted for in the children's ability to use prepositions if chronological age alone is considered. Almost 67 per cent of the

TABLE II

ANALYSIS OF VARIANCE TABLE FOR THE REVISED

EXPRESSIVE PREPOSITION TEST

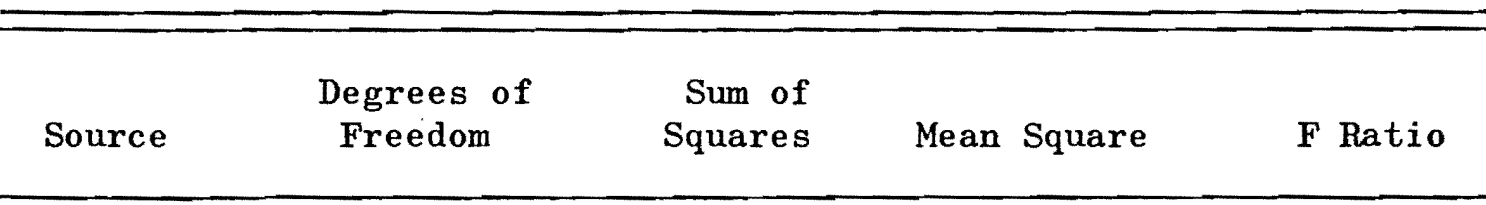

Variable: Age

$\begin{array}{lcccc}\text { Regression } & 1 & 245.86989 & 245.86989 & 3.87682 \\ \text { Error } & 43 & 272.70789 & 6.34204 & \mathrm{R}^{2}=.4741 \\ & & & \mathrm{R}=.6886\end{array}$

Variables: Age and Intelligence

$\begin{array}{lcccc}\text { Regression } & 2 & 349.02662 & 174.51331 & 4.32292 \\ \text { Error } & 42 & 169.55116 & 4.03693 & \mathrm{R}^{2}=.6730 \\ & & & \mathrm{R}=.8204\end{array}$

Variables: Age, Intelligence and SES

$\begin{array}{lrrrr}\text { Regression } & 5 & 357.58664 & 71.51733 & 1.73250 \\ \text { Error } & 39 & 160.99113 & 4.12798 & \mathrm{R}^{2}=.6896 \\ & & & & \mathrm{R}_{.}=.8304\end{array}$

Significant at 0.001 level.

variability can be accounted for if mental age is considered with chronological age. When SES is considered with both mental and chronological age, less than 2 per cent is added to account for the total 
variability. Thus it is statistically significant at the .001 level of confidence that chronological age was the primary variable determining the children's ability to use prepositions.

The fifth question in this investigation was how appropriate was the REPT as a diagnostic tool of very young children's ability to express prepositions. The REPT was appropriate in that all stimuli were very short in length, with the semantics and syntax at an elementary level. The children appeared to respond quicker when the examiner introduced the toy objects used in the test than when he was just conversing with them.

\section{DISCUSSION}

This study was designed to determine at what ages very young children verbally and correctly express a total of fourteen different prepositions. The main question asked was, "Which of the various fourteen prepositions appear at eighteen months, at twenty-four months, at thirty months, at thirty-six months and at forty-two months?" It was found that as a group, eighteen and twenty-four month olds did not use prepositions, although individual children expressed a few prepositions. At the thirty month level, four prepositions ("under," "on," "in" and "up") appeared in their expressive language. At the thirty-six month level, four prepositions appeared in their expressive language, of which two ("in" and "up") were the same as the thirty month olds and two ("out of" and "at") were not. "Under" and "on" were expressed by many (42 per cent) of the thirty-six month olds but not by at least half of them. At the forty-two month level, ten prepositions appeared of which two ("out 
of" and "at") were the same as the thirty-six month olds, two ("under" and "on") were the same as the thirty month olds, two ("in" and "up") were the same as both the thirty and thirty-six month olds, and four ("to," "around," "of" and "with") were not the same as either group. Four prepositions ("behind," "across," "off" and "by") did not appear in the language of the children as a whole, that is, less than half of the children at any one age level used these four prepositions. Hustead (1974) reported that these four prepositions appeared in the language of her forty-eight month olds (at least half of them), which suggested that most children expressively acquire these prepositions around forty-eight months.

As depicted in Table II, the analysis of the data reveals a moderate (.68) correlation between the chronological age of the child and the ability to use prepositions (Guilford, 1956). Table I and Figure 4 indicate that up through the forty-two month level, each age level progressively used a greater number of correct responses. The only exception is at the thirty-six month level where the children gave 4.92 correct responses on the average, which is a decline when compared to the thirty month level where an average of 5.50 correct responses were given. Hustead (1974) intimated that when her eight year olds produced more correct responses than her nine year olds, a greater number of subjects were required for the study at each age Ievel so that individual abilities to use prepositions might be minimized. As illustrated in Figure 5, the thirty, thirty-six and forty-two month levels show a wide range of individual scores, which suggests the need for more subjects at each level. Although twelve children were tested at each level, 
there appears to be rather large variability in linguistic skills among children at these early ages.

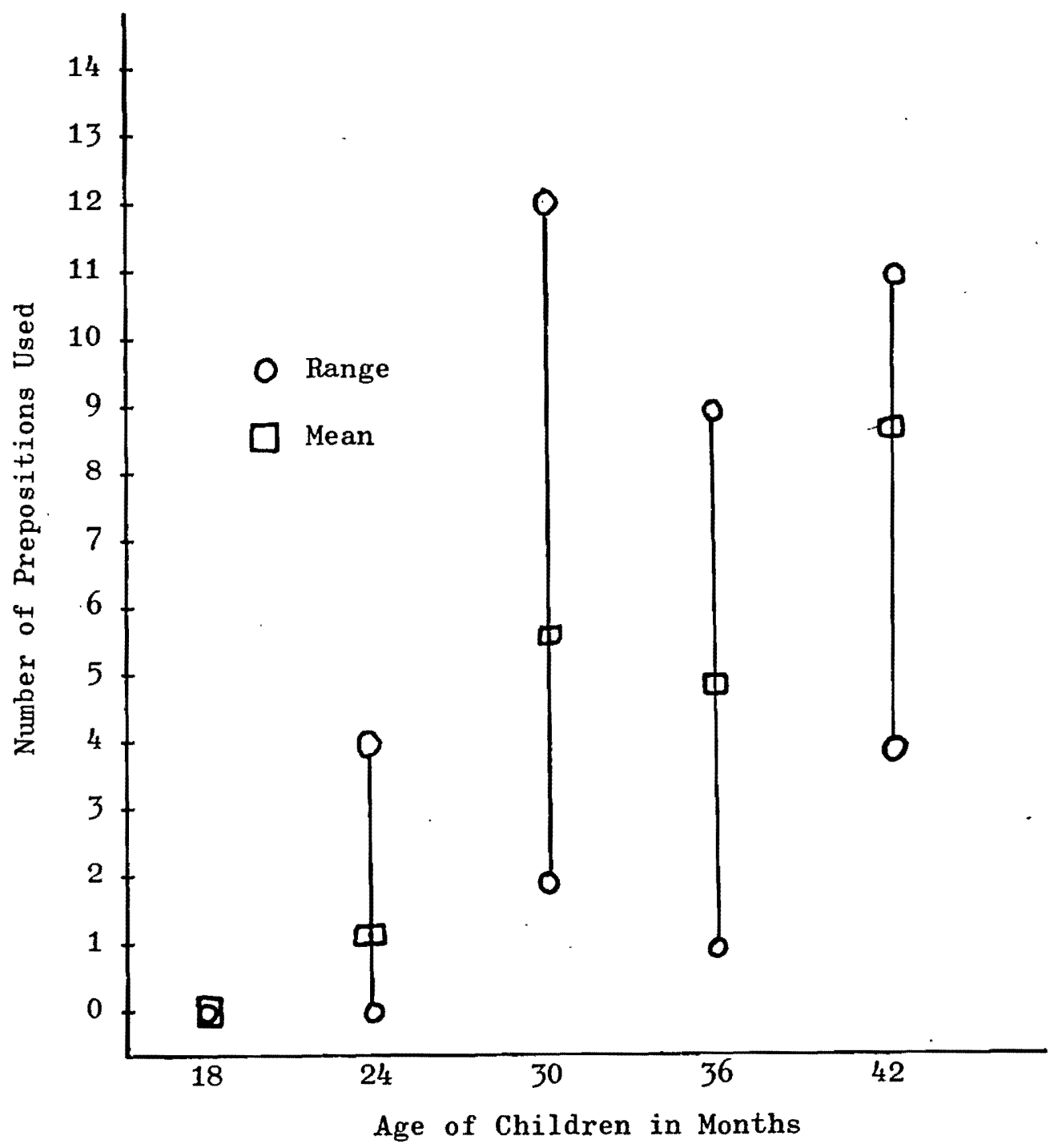

Figure 5.' Ranges and means of REPT scores of the sixty children ranging in age from eighteen to forty-two months.

Additionally, Table $I$ and Figure 4 do not reveal six eighteen month olds who were excluded from the study because they did not meet the language requirement of ten expressive words. It was more difficult to locate eighteen month olds meeting normal language requirement than to locate all other age levels meeting the normal language requirement. 
Obviously, from the nature of the limited vocabulary of the eighteen month olds (nouns and verbs), there is low probability for finding expressive prepositions. The use of short sentences and the frequent use of holophrases at this age limit the probability of the child expressing functors.

Table II shows there was a high positive correlation (.82) between the child's mental age (when added to chronological age) and his ability to use prepositions (Guilford, 1956). Of the sixty children in the study, eleven eighteen month olds, three twenty-four month olds and one thirty month old did not respond to the mental age test. These fifteen children were excluded from the statistical analyses of the data. Based on the remaining forty-five children, it appears that intelligence made some contribution to the child's expressive preposition ability. Both the twenty-four and forty-two month old groups received mean intelligence quotients of 88 . The thirty month old group received a mean intelligence quotient of 99 ; however, the thirty-six month old group received a mean intelligence quotient of 79 . The difference between these last two scores is 20 points. Not only did the thirty month olds perform better than the thirty-six month olds on the intelligence test, they also performed better on the REPT. These data suggest that intelligence and ability to express prepositions may have a substantially greater relationship than was expressed when the data were collapsed. The mean chronological age of the forty-five children was 33.33 months and the mean mental age was 29.13 months which yields a mean intelligence quotient of about 87 , which is a score within the "dull normal" range (Terman and Merrill, 1937). This re- 
searcher has no reason to suspect that the sample of children was below normal intelligence and suspects that intelligence scores of the children should be interpreted with some caution. First of all, a number of researchers (Anderson, 1939; Bayley, 1933; Cattell, 1940; Kessen et al., 1970; Wittenborn, 1957) agree that the reliability of intelligence testing at such early ages is very suspect, as young children's performances tend to fluctuate significantly from day to day. Secondly, the Quick Test (Ammons and Ammons, 1962), which was used to measure mental ages of children in this study, largely tests comprehensive vocabulary not expressive. This method of testing mental age may have been penalizing to some children who were of normal or high intelligence, in that they simply did not attenuate to the difficult vocabulary when the test was administered. Third, the lower testing limit of the Quick Test is at eighteen months, which is the lowest age level of subjects in the present study. Boyd (1975) has pointed out that mental age testing of eighteen month olds using the Quick Test was "riding at the bottom" of the scale and may not have been an appropriate tool. In summary, this researcher feels the mental age scores of children in this study are somewhat suspect, although chronological and mental age accounts for twothirds $(.67)$ of the total variability.

Additionally, Table II reveals there was little correlation between the child's SES (when the effect is added to chronological and mental ages) and his ability to use prepositions (.83). Hustead (1974) hypothesized that SES would be a greater determining factor for two and three year olds than for older children since the younger ones spend the majority of their time in the home; however, based upon the present study, 
this appears not to be the case.

The 31 per cent of unaccounted variability in the REPT score may be explained by several variables. First, there was no record of how much time a language model was provided for the child as he acquired and used language. The more a parent talks and reads to the child, the greater the child's opportunities are for learning language. Second, there was no record of the amount of time the child spent watching educational television. These types of programming also provide language models from which children acquire vocabulary. Finally, the number of children in the family and the ordinal position of the child in the family was not recorded in the present study. According to Winitz (1969), the first born child is further advanced in language than the rest of his siblings, and twins tend to be slower in language development. One may want to adjust for these factors.

Prepositions of time were not tested in the present study; however, the results of this study agreed with Menyuk's (1969) results which indicated children tended to learn prepositions of place before those of manner. The prepositions used by at least half of the thirty month olds ("under," "on," "in" and "up") were prepositions depicting place. Three prepositions of place ("at," "in" and "up") were expressed by the thirty-six month olds as well as one preposition of manner ("out of"). Half of the prepositions used by the forty-two month olds were ones of place ("under," "at," "up," "in" and "on") and half were ones of manner ("to," "out of," "around," "of" and "with").

The findings of this study also agreed with previous studies that children tend to acquire and express prepositions a few at a time rather 
than as a whole class (Lillywhite, 1958). Of the five prepositions listed by Bereiter and Engelmann (1966) which beginning school age children should have, 100 per cent of the forty-two month olds in the present study correctly expressed "on" and "in" and 67 per cent "under." The remaining two prepositions ("over" and "between") were not tested in the present study.

The ability of young children to use prepositions measured in this study agrees with the guidelines given in the Sequenced Inventory of Language Development (SILD) (Hedrick and Prather, 1970). On the SILD 75 per cent of the thirty to thirty-two month olds used the prepositions "in" and "on" and 75 per cent of the thirty-nine to forty-one month olds used "under" and "beside." In the present study 92 per cent of the thirty month olds expressed "in" and 67 per cent expressed "on." of the forty-two month olds 67 per cent used "under"; however, if, as Hustead (1974) and Hedrick and Prather (1970) suggested, "by" and "beside". are equal semantically, only 42 per cent of the forty-two month olds expressed the correlate of "beside." Children in this study performed differently than those children in the SILD study for perhaps several reasons. First of all, most of the children used in the SILD study were of families in which at least one parent was working toward a university degree. Children of parents with higher education tend to be advanced in their language over children of parents without higher education (Anderson and Newby, 1973; Raph, 1969; Templin, 1957). In the present study the parents of the children were not necessarily working toward a degree nor were they graduates from an institution of higher education. Secondly, in the SILD the number of children in each age level interval 
ranged from four to eight. In the REPT the number of children in each age level was twelve. Since the REPT had a larger number of children at each level, the REPT would tend to have greater validity with respect to number of subjects. Finally, both the SILD and REPT are only preliminary investigations, and both tests' norms are tentative, needing further standardization.

There is partial agreement between the linguistic performance of the children in the present study and the linguistic performance suggested by the Developmental Age Study (DAS) (Baker and Dudrey, 1968; Table II). Agreements and disagreements between the DAS and REPT findings cannot be dealt with meaningfully as the DAS was an instrument which consisted of an extensive review of the traditional literature and was not a field study. The authors (Baker and Dudrey, 1968) do not state where they acquired their data, the number of subjects used to acquire the data, how the responses were elicited or how the responses were interpreted.

Because this p̀resent investigation and the SILD suggest that young children tend to express prepositions at different age levels, there appears to be a need for normative data on the expressive acquisition of at least fourteen prepositions, utilizing a larger population. This researcher concurs 'with Hustead's (1974) suggestion that testing begin at two years of age.

It is this researcher's clinical impression that some of these very young children may have been unduly handicapped by their unfamiliarity with the language of the stimuli items used by the researcher when eliciting the prepositions, i.e., if the child did not comprehend the 
concept "where," then he would have no idea what the researcher was asking on stimuli items 1, 2, 4 through 9, 13 and 14. In other words, the child would not have been "handicapped" on only 4 of the 14 prepositions tested (Appendix E). It is conceivable that some of the children were penalized because they did not understand even short sentences, such as on stimuli items 8 through 12 (Appendix E). The length of the utterances on 9,11 and 12 might be too long for the children to analyze and comprehend. Admittedly, it would be very difficult to test expressive prepositions or other aspects of language without the use of language itself.

The REPT itself may be improved in several aspects. First, the order of the prepositions administered to the subjects should be altered. Table III lists the number of times each preposition was used by the subjects. "By" was administered first and was expressed by only seven of the sixty subjects. This lack of occurrence may be explained, in part, because the children initially may not have understood they were to describe verbally where an object was in relation to some other object. This penalizing phenomenon may decrease if the REPT would have begun with "in" or one of the other often occurring prepositions. The low occurrence of "across" (only five of sixty times) cannot be explained this way. Although incorrect responses were not recorded, this researcher recalls that many of the prepositions tested were substituted by a word which embodied part of the semantics of the preposition tested. For example, "on" was often used as a substitute for "across"; this seems logical as the total semantic field of "on" is carried in part of the semantic field of "across." Thus, for the child, "on" was 
TABLE III

FREQUENCY OF OCCURRENCE OF PREPOSITIONS

USED BY ALL CHILDREN

\begin{tabular}{|c|c|c|}
\hline Preposition & $\begin{array}{c}\text { Number of Times } \\
\text { Expressed }\end{array}$ & $\begin{array}{c}\text { Total Number } \\
\text { Possible }\end{array}$ \\
\hline In & 35 & 60 \\
\hline Up & 34 & 60 \\
\hline on & 28 & 60 \\
\hline At & 21 & 60 \\
\hline Under & 20 & 60 \\
\hline out of & 18 & 60 \\
\hline $0 f$ & 17 & 60 \\
\hline With & 17 & 60 \\
\hline To & 14 & 60 \\
\hline Around & 13 & 60 \\
\hline off & 10 & 60 \\
\hline By & 7 & 60 \\
\hline Across & 5 & 60 \\
\hline Behind & 1 & 60 \\
\hline
\end{tabular}

a logical substitution for "across." The infrequent occurrence of "behind" (one time) makes the test stimuli or materials, as well as their location in the test, highly suspect. It may be possible also that children who are forty-two months and under do not use the word "behind" until some time later in life. This is supported by Hustead's 
data (1974) in which she reported that of her four year olds only four of six expressed "behind." In summary, it appears that either something is amiss with the REPT's method or procedures for eliciting "behind," or the concept of "behind" begins appearing somewhere between forty-two and forty-eight months. 


\section{CHAPTER V}

\section{SUMMARY AND IMPLICATIONS}

\section{SUMMARY}

Many linguistic analyses of the English language have shown the important use of prepositions. However, little, if any, normative data have been collected on the acquisition of expressive prepositions by very young children.

The present study was designed to determine the ages at which a sample of children between eighteen and forty-two months verbally and correctly express the fourteen prepositions known to be acquired by age four, using the Revised Expressive Preposition Test (REPT). The REPT was administered to sixty children chosen from day care centers and private homes within the metropolitan area of Portland, Oregon. There was no preference as to the sex, intelligence of the child or socioeconomic status of the child's family. A statistical analysis was performed to determine the correlation between REPT scores and the child's chronological age, mental age and the socioeconomic status of the child's family.

Results show that expressive prepositions tend to be acquired at different age levels. Each age group tended to use a progressively greater number of the prepositions. None of the eighteen month olds used any of the prepositions. Only one-fourth of the twenty-four month olds used any of the prepositions. Half or more of the thirty month 
olds expressed the prepositions "under," "on," "in" and "up." Half or more of the thirty-six month olds expressed the prepositions "out of," "at," "in" and "up," but not "under" and "on." Half or more of the forty-two month olds expressed the prepositions "to," "out of," "under," "around," "at," "of," "with" and "up." One hundred per cent of the forty-two month olds also used the prepositions "in" and "on." The prepositions which were never expressed by 50 per cent of any of the children were "behind," "across," "off" and "by."

A statistical analysis of the data revealed a moderate correlation between the children's REPT scores and their chronological ages (.68). Correlation coefficients indicated a high correlation between the children's REPT scores and their combined chronological and mental ages (.82). The children's SES scores did not correlate with REPT scores (1 per cent) when considered together with chronological and mental ages. The results of the REPT agreed with the results of Hedrick and Prather's (1970) study that "in" and "on" appeared in the expressive vocabulary of thirty month olds. According to the present study and Hustead's (1974) study, "under" appeared consistently from the forty-two month level on up. Hedrick and Prather (1970) agreed that "under" appeared at forty months in their study. The results of the above three studies are strikingly similar.

Four prepositions ("behind," "across," "off". and "by") did not appear in the language of the children in the present study. Hustead (1974) has reported that these prepositions appeared in the vocabulary of her forty-eight month olds. 
II. IMPLICATIONS FOR CLINIC AND FUTURE RESEARCH

$\underline{\text { Clinic }}$

Although no supportive data were recorded, it is this researcher's clinical impression that some of the responses given by the children were prepositions which overlapped in their meanings with the correct prepositions. At times, the substituted preposition could in certain semantic contexts be used interchangeably with the correct preposition. Therefore, when a clinician or parent is teaching a child expressive prepositions and the child says "from" instead of "out of," the clinician or parent should accept the response as correct.

Results of the present study suggest that prepositions of place appear before prepositions of manner and time. If a child is delayed in expressive prepositions, the teaching of prepositions of place should precede those of manner and time.

Once the child has learned to appropriately express the various prepositions, the parent may also wish to teach the child additional meanings or shades of meanings of the prepositions.

\section{Research}

A significant trend exists which reveals that as children become older, they begin expressing more prepositions, indicating the need for a larger number of subjects for a normative data study. The present study further indicates that future testing may begin at twenty-four months and proceed upward.

This researcher attempted to have each child and examiner begin a conversational relationship within ten minutes after the beginning of 
the interview. It is recommended that in future testing the child be tested at three or four different times and his best performance be scored and interpreted. Very young children need to have more time than older children to become familiar with a novel person such as an investigator.

Table III indicated that only one out of the sixty children tested expressed the preposition "behind." It is recommended that in future testing a different procedure be used to elicit that preposition, with the hope of increasing the number of correct responses. Hustead (1974) reported that this preposition was a little unstable in her subjects' language. With a sample of six children at each yearly interval, four of her four year olds, six, of her five year olds, five of her six year olds and all of her seven through nine year olds used the word. This researcher suspects that either the procedure used in this study to elicit the preposition is in question for some unrealized reason or that the preposition is unstable until around forty-eight months.

In the present study the investigator attempted to elicit prepositions while focusing the subject's attention upon stimulus materials which were apart from the subject himself. It is recommended the prepositions "behind" and "under" be elicited by placing the object behind and under the chair of the subject. If the child uses himself as the point of reference from which he must analyze a situation, he may be able to describe the location of the object by using the correct preposition.

Normal language for all eighteen month olds was determined by requesting the parent to report ten words in the child's expressive 
vocabulary. It is recommended that the parent be not instructed to report ten words but all the words the child uses. Therefore, a parent may not feel it necessary to "make up" expressive words to meet the ten word criterion. Should a parent be unable to report ten words in the child's vocabulary, the child would be excluded from the study.

This study sought to find out to what extent chronological age, mental age and SES account for a child's expressive preposition acquisition. It is suggested that the amount of time a language model was provided for the child as he acquired language be recorded. This researcher suspects that the more one talks and reads to a child, the greater the child's opportunities are for learning vocabulary. Additionally, it is suggested that the amount of time a child spends watching children's educational programs on television be recorded. This researcher suspects that children watching these types of programing tend to learn language quicker than children who do not. 


\section{REFERENCES}

AMMONS, R. B., and AMMONS, C. H., Quick Test. In Psychological Reports, Mono. Supplement I-VII, 111-161 (1962).

ANDERSON, L. D., The predictive value of infancy tests in relation to intelligence at five years. Child Development, 10, 203-212 (1939).

ANDERSON, V. A., and NEWBY, H. A., Improving the Child's Speech. (2nd ed.) New York: 0xford University Press (1973).

ASCH, S. E., and NERLOVE, N., The development of double function terms in children: An explanatory investigation. Perspectives in Psychological Theory: Essays in Honor of Heinz Werner, B. Kaplan and S. Wagner (Eds.), New York: International University Press, 1960 , as cited in P. Menyuk, The Acquisition and Development of Language. Englewood Cliffs: Prentice-Hall, Inc. (1971).

BAKER, T., and DUDREY, M., Developmental Age Study. Portland, 0regon: Special Education, Portland Public Schools (1968).

BAYLEY, N., The California First-Year Mental Scale. Berkeley: University of California Press (1933).

BEREITER, C., and ENGELMANN, S., Teaching Disadvantaged Children in the Preschool. Englewood Cliffs: Prentice-Hall, Inc. (1966).

BLOOM, L., Why not pivot grammar? J. Speech Hearing Dis., 36, 40-50 (1971).

BOEHM, A. E., Boehm Test of Basic Concepts. New York: Psychological Corp. $(1 \overline{969)}$.

BOYD, R., Comment Made in Personal Communication, June, 1975.

BRAINE, M. D. S.ं, The ontogeny of English phrase structure: The first phase. Language, 39, 1-13 (1963).

BROWN, R., and BELLUGI, U., Three processes in the child's acquisition of syntax. Harvard Educational Review, XXXIV, 133-151 (1964).

BROWN, R., and FRASER, C., The acquisition of syntax. Child Development Mono., 29, 43-79 (1964). 
CATTELL, P., The Measurement of Intelligence of Infants and Young Children. New York: Psychological Corp. (1940).

CHOMSKY, N., Syntactic Structures. The Hague: Mouton (1957).

CRABTREE, M., Houston Test for Language Development. Houston: Houston Test Co. (1963).

DANZER, V. A., GERBER, M. F., and LYONS, T. M., Daberon. Portland, Oregon: Daberon Research (1972).

DEWEY, G., Relative Frequency of English Speech Sounds. Cambridge: Harvard University Press (1923).

ERVIN-TRIPP, S. M., Language development. Review of Child Development. L. W. Hoffman and M. L. Hoffman (Eds.), New York: Russel Sage Foundation (1966), as cited in P. Menyuk, The Acquisition and Development of Language. Englewood Cliffs: Prentice-Hall, Inc. (1971).

FRANKENBURG, W. K., and DODDS, J. B., Denver Developmental Screening Test. Boulder: University of Colorado Medical Center (1967).

FRENCH, N. R., CARTER, C. W., JR., and KOENIG, W., JR., Words and sounds of telephone conversations. Bell System Technical J., IX, 290$310(1930)$.

FRIES, C., American English Grammar. New York: Appleton-CenturyCrofts, Inc. (1940) as cited in A. H. Streng, Syntax, Speech and Hearing. New York: Grune and Stratton (1972).

FRIES, C., The Structure of English. New York: Harcourt, Brace, and World (1952).

GUILFORD, J. P., Fundamental Statistics in Psychology and Education. (3rd ed.) New York: McGraw-Hill Book Company, Inc. (1956).

HEDRICK, D., and PRATHER, E., Sequenced Inventory of Language Development. Seattle: University of Washington and Child Development and Mental Retardation Center (1970).

HOPPER, R., and NAREMORE, R. C., Children's Speech: A Practical Introduction to Communication Development. New York: Harper and Row (1973).

HUSTEAD, G., Age, intelligence, and socioeconomic status variance in preposition acquisition by children. Unpublished Master's thesis, Portland State University (1974). 
KESSEN, W., HAITH, M., and SALAPATEK, P., Human Infancy: A Bibliography and Guide, in Carmichael's Manual of Child Psychology, P. H. Mussen (Ed.), New York: John Wiley \& Sons, Inc. (1970).

KORZYBSKI, A., Science and Sanity. Lakeville: International NonAristotelian Library Co. (1958).

LEE, L., Brain damage and the power of abstracting. ETC, XVI, 154-162 (1959).

LEE, L., Developmental sentence types: A method for comparing normal and deviant syntactic development. J. Speech Hearing Dis., 31 , 311-330 (1966).

LEOPOLD, W. F., Semantic Learning in Infant Language. In A. Bar-Adon and W. Leopold (Eds.), Child Language: A Book of Readings. Englewood Cliffs: Prentice-Hall, Inc. (1971).

LEWIS, M. M., Language, Thought and Personality. New York: Basic Books, Inc. (1963) as cited in P. Menyuk, The Acquisition and Development of Language. Englewood cliffs: Prentice-Hall, Inc. (1971).

LILLYWHITE, H., Doctor's Manual of Speech Disorders. The J. of American Medical Association, CLXVII, 850-858 (1958).

LUMSDEN, E. A., and POTEAT, B., The salience of the vertical dimension in the concept of "bigger" in 5 and 6 year olds. J. Verbal Learning and Verbal Behavior, 7, 404-408 (1968).

McNEILL, D., The Acquisition of Language. New York: Harper \& Row $(1970)$.

MECHAM, M., JEX, J., and JONES, J., Utah Test of Language Development. Salt Lake City: Communication Research Associates, Inc. (1969).

MENYUK, P., Comparison of grammar of children with functionally deviant and normal speech. J. Speech Hearing Res., 7, 109-121 (1964).

MENYUK, P., Sentences Children Use. Cambridge: MIT Press (1969).

MENYUK, P., The Acquisition and Development of Language. Englewood Cliffs: Prentice-Hall, Inc. (1971).

MILLER, W., and ERWIN, S., The development of grammar in child language. Child Development Mono., 29, 9-34 (1964).

PALFRM0, D., and JENKINS, J. J., Changes in word associations of 4 th and 5 th grade children from 1916 to 1961 . J. Verbal Learning and Verbal Behavior, 4, 180-187 (1965). 
PIERCE, J. E., A statistical study of grammar and lexicon in Turkish and Sahaptin (Klikitat). International Journal of American Linguistics, II, 96-106 (1963).

PIERCE, J. E., The morphemes of English: Unbound minor morphemes. Linguistics, XLVII, 41-73 (1969).

QUINE, W., Speaking of objects. In J. Foder and J. Katz (Eds.), The Structure of Language. Englewood Cliffs: Prentice-Hall, Inc. (1964).

RAPH, J. B., Language Development in Socially Disadvantaged Children. In P. Burns and L. M. Schell (Eds.), Elementary School Language Arts: Selected Readings. Chicago: Rand McNally (1969).

SLOBIN, D. I., Soviet psycholinguistics. In N. 0'Conner (Ed.) Present Day Russian Psychology: A Symposium by Seven Authors, 0xford, England: Pergamon Press (1966) as cited in P. Menyuk, The Acquisition and Development of Language. Englewood Cliffs: PrenticeHall, Inc. (1971).

STRENG, A. H., Syntax, Speech and Hearing. New York: Grune and Stratton $(1972)$.

TEMPLIN, M., Certain Language Skills in Children. Minneapolis: University of Minnesota Press (1957).

TERMAN, L. M., and MERRILL, M. A., Measuring Intelligence: A Guide to the Administration of the New Revised Stanford-Binet Tests of Intelligence. Cambridge, Mass.: The Riverside Press (1937).

UNIVERSTTY OF OREGON MEDICAL SCHOOL, Crippled Children's Division, Language Manual, Portland (1957).

U.S. BUREAU OF THE CENSUS, Working Paper Number 15: Methodology and Scores of Socioeconomic Status. Washington, D. C. (1963).

VYGOTSKY, L. S., Thought and Language. Cambridge: MIT Press (1962) as cited in P. Menyuk, The Acquisition and Development of Language. Englewood Cliffs: Prentice-Hall, Inc. (1971).

WALES, R. J., and MARSHALL, J: C., The organization of linguistic performance. In J. Lyons and R. J. Wales (Eds.), Psycholinguistic Papers. Chicago: Aldine (1968), as cited in P. Menyuk, The Acquisition and Development of Language. Englewood Cliffs: Prentice-Hall, Inc. (1971).

Webster's Seventh New Collegiate Dictionary. Springfield, Mass.: G. \& C. Merriam Company (1969). 
WEIR, R., Language in the Crib. The Hague: Mouton (1962).

WERNER, H., and KAPLAN, B., Symbol Formation. New York: John Wiley \& Sons, Inc. $(1964)$.

WINITZ, H., Articulatory Acquisition and Behavior. New York: AppletonCentury-Crofts (1969).

WITTENBORN, J. R., The Placement of Adoptive Children. Springfield, I11.: Thomas (1957). 


\section{APPENDIX A}

\section{COMPREHENSION OF FOUR PREPOSITIONS \\ BY CHRONOLOGICAL AGE \\ (Crabtree, 1958)}

Prepositions tested: "on," "under," "in front of" and "behind"

24 Months: 'Comprehends one of the prepositions.

30 Months: Comprehends two of the prepositions.

36 Months: Comprehends three of the prepositions.

48 Months: Comprehends all four of the prepositions. 


\begin{abstract}
APPENDIX B
COMPREHENSION OF VARIOUS PREPOSITIONS

BY CHRONOLOGICAL AGE

(University of Oregon Medical School, 1957)
\end{abstract}

30 Months

Responds to: "on," "under," "up," "down," "over there," and "by" when used in complete sentences.

36 Months

Responds to two related actions: "Run over to the chair and sit down."

42 Months

Follows commands: "Find the ball on the table and give it to mother." Or: "Find the spoon in the box and give it to daddy."

48 Months

Comprehends: "Take the book from the table and give it to mother."

54 Months

Responds to: "Take the dolly to mother, open the door, and bring in the baby buggy." 


\section{APPENDIX C \\ PERCENTAGE OF PREPOSITIONS COMPREHENDED WHEN \\ VARIABLES OF AGE AND SOCIOECONOMIC \\ STATUS ARE CONSIDERED \\ (Frankenburg and Dodds, 1967)}

Prepositions tested: "on," "under," "in front of," and "behind" Age when given per cent of population comprehended prepositions tested:

Comprehension of the prepositions, based on the total sample

\begin{tabular}{llll}
\hline $25 \%$ & $50 \%$ & $75 \%$ & $90 \%$ \\
\hline $2.7 \mathrm{yrs}$. & $3.1 \mathrm{yrs}$. & $3.4 \mathrm{yrs}$ & $4.5 \mathrm{yrs}$.
\end{tabular}

Comprehension of the prepositions, based on occupation groups

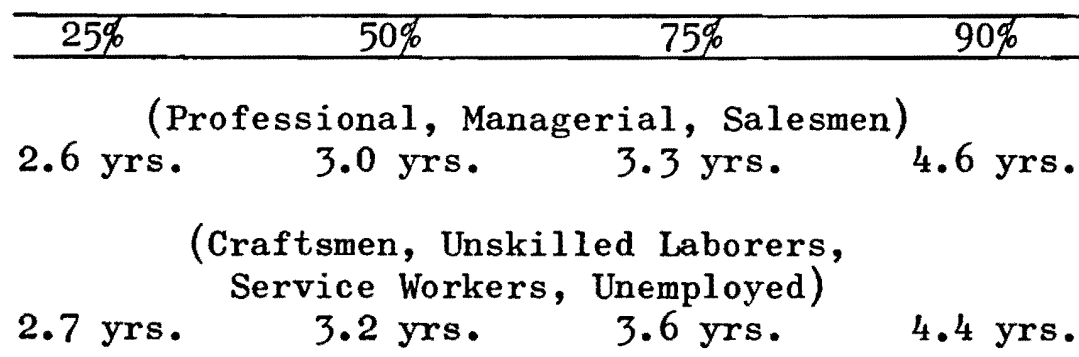




\section{APPENDIX D}

CCD-CDRC HEARING SCREENING SCHEDULE

Age

8-15 mos. (babbling-vowels \& consonants

16-24 mos. (understands

a few words

\section{Materials}

Quiet, meaningful sounds. Voice (whistle, name or sh), cellophane, spoon-in-cup or noisemakers above

\section{Voice \& 3 toys to} identify (baby, bird, shoe or car)

2 years up

As above. Use any $4-5$ objects he "knows"

3 years up Audiometer

\section{Procedures}

Present sounds at 3-4' from ear, alternate sides

In soft voice, call child's name, gives objects ask him to show you objects or to point to eyes, nose, hair

As commands, stand up, follows commands sit down, shut the door

Screening audiometry, $1,2,4 \&$ $.5 \mathrm{KHz}$ at $20-25 \mathrm{~dB}$ right and left

\section{Responses} Child may also vocalize as a response

\section{Child points or} beep) is heard
Turn head or eyes toward sound, eye widening, quieting.

Within normal limits

$3 / 4 \quad$ As above

$8 / 8$

Raise hand, touch phone, or say "yes" when tone (whistle,

\section{Criteria Interpretation}

$2 / 3$

Rules out all but mild loss 


\section{APPENDIX E}

\section{SENTENCES USED TO ELICIT THE FOURTEEN PREPOSITIONS}

\section{Stimulus}

1. Where is the car?

2. Where is the car?

3. What did I do?

4. Where is the car?

5. Where is the car?

6. Where is the car going?

7. Where is the car?

8. Where would you buy these shoes?

\section{Procedure}

(The examiner places a small car by a box.)

(The examiner places a small car in a box.)

(The examiner takes the car out of the box.)

(The examiner places a small car on a box.)

(The examiner places the car under the box.)

(The examiner moves the car around the box.)

(The examiner places the car behind the box.)

(The examiner shows the child a pair of baby shoes.)
Response

By the box. Beside the box. Alongside the box. Next to the box.

In the box. Inside the box.

You took the car out of the box.

on the box.

Upon the box.

Under the box. Below the box. Beneath the box.

Around the box. About the box.

Behind the box. In back of the box.

At the store. 
Stimulus

9. Here is a bridge and here is a river. Where is the car going?

10. How do you eat cereal?

11. I put the car on the box. Now I take it

12. Here is the boy going up the mountain. Now he is on top

13. Where did the boy go?

14. Where is the boy walking?
Procedure

(The examiner shows the child a toy bridge and slowly moves a car across the bridge.)

(The examiner shows the child a spoon.)

(The examiner puts the car on the box, then slowly takes it off, out of sight.)

(The examiner walks a doll up the side of a toy mountain, then holds the doll on top of the mountain.)

(The examiner "walks" the boy to the car.)

(The examiner "walks" the doll up the mountain.)
Response

Across the bridge. 0ver the bridge.

With a spoon.

Off the box. off of the box.

of the mountain.

To the car.

Up the mountain. 